\title{
Colectivo Obrero, Trabajo y Educación: Escenas Madrilenas del Trabajo Industrial en la Guerra Civil Española*
}

\section{Lia Vargas Tiriba}

Universidade Federal Fluminense (UFF)

Ao se constituir como uma frente popular de luta contra o fascismo, a guerra civil espanhola (1936-1939) promoveu mudanças significativas na estrutura do Estado e nas diferentes instâncias da sociedade. Socializados os meios de produção, as coletividades operárias e camponesas ensaiaram os primeiros passos em busca de uma outra lógica para a articulação entre o mundo da cultura e o mundo da produção, tendo como perspectiva a construção de uma nova ordem social inspirada nos princípios do socialismo. Neste artigo reconstituímos a história da Asociación Colectivade Trabajo Almacenes Quirós (ACTAQ) e, para compreender as dimensões da relação entre trabalho e educação no interior da fábrica, nos perguntamos: No cenário político, económico e social da revolução popular, quais os desafios da produção? Quais os objetivos do Conselho Operário no processo de educação dos demais trabalhadores coletivos? Que concepções de trabalho e de mundo estavam subjacentes ao processo educativo? Em que medida as práticas de trabalho, inspiradas nos princípios stajanovistas, iam em sentido contrário ao ideário de homem e de sociedade? Em que medida a vida cotidiana no chão-de-fábrica contrariava/reproduzia a lógica da organização capitalista de trabalho?

-Este artículo es síntesis de la investigación presentada como trabajo final dei curso "Arqueologia industrial, arqueologia dei trabajo" (1994-1995), dirigido por los professores Juan José Castillo e Mercedez Lopes Garcia, com la colaboración de Paloma Candeia - Doctorado en Sociologia Económica y dei Trabajo de la Facultad de Ciências Políticas y Sociologia de la Universidad Complutense de Madrid, Espana. Adradezco a la Andrea dei Bono, de la Universid Nacional de la Plata, Argentina, por sus sugerencias y por su paciência en la revisión de los originales. 
La explotación y degradación dei trabajo, historicamente impuestos por la forma capitalista de producción, trae aparejado para los trabajadores el desafio de creación y recreación de nuevas relaciones en el âmbito de lo cotidiano fabril y de las demás instancias de la vida en sociedad. Además de la historia "oficial" dei capitalismo, en que la educacion suele ser concebida como "preparación" o "perfeccionamiento" para el mercado de trabajo, es importante no olvidar algunos capítulos de la historia de la humanidad en que los trabajadores mismo fueron los actores-protagonistas de la búsqueda de otra lógica para la articulación entre el mundo de la cultura y el mundo de la producción. Concibiendo lo cotidiano fabril como instancia de educacion de los trabajadores, como locus de producción de una nueva organización dei trabajo y de una nueva relación trabajo-educación, en este ensayo nos gustaría destacar las experiências de las colectividades obreras en el período de la guerra civil espanola (1936-1939). Para nuestra reflexión sobre el significado de la educacion en los movimientos contradictorios dei proceso de creación de nuevas maneras de hacer y concebir el trabajo, elegimos la Asociación Colectiva de Trabajo Almacenes Quirós (ACTAQ), industria de géneros de punto, con cerca de 500 trabajadores, localizada en la ciudad de Madrid, fundada en 1893 y que, durante la revolución popular fue incautada por el Estado. En el escenario político, económico y social de la guerra ^cuáles eran los desafios de la producción? ${ }^{\wedge}$ Cuáles los objetivos dei Consejo Obrero en el proceso de educacion de los demás trabajadores colectivos? i,Qué concepciones de trabajo y de mundo estaban subyacentes en el proyecto de educacion? ${ }^{\wedge}$ En qué medida las prácticas laborales, inspiradas en los princípios stajanovistas, iban en sentido contrario ai ideário de hombre y de sociedad? ${ }^{\wedge}$ En qué medida la vida cotidiana en el interior de la fábrica contrariaba/reproducía la lógica de la organización capitalista dei trabajo?

Además de reconstituir la relación trabajo-educación "a pie-de-lafábrica", creemos que recuperar los datos de una industria incautada por el Estado - representado por el Gobierno Republicano - es un intento 
de recuperación de la historia del trabajo bajo la versión de los propios trabajadores, sin olvidar la complejidad del contexto y la diversidad de concepciones políticas e ideológicas de los actores de la revolución popular. La singularidad de Almacenes Quirós ${ }^{1}$ radica en que allí, los actores protagonistas de la colectivización no eran los anarquistas ni los trotskistas - como solía ser en la historia de la guerra civil española. Aunque estas fuerzas estuvieran presentes y representadas en el Consejo Obrero, eran los comunistas quienes tenían la hegemonia política del proceso de reorganización de la producción. Es decir, se constituían como fuerza mayoritaria de Almacenes Quirós aquellos actores sociales que eran acusados de luchar contra las colectividades obreras y campesinas que, en la revolución popular eran consideradas como elementos de constitución de una nueva cultura de trabajo y de una nueva sociedad.

Para reflexionar sobre la historia dei trabajo en una colectividad

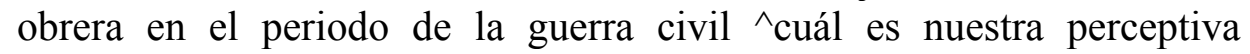
metodológica? De acuerdo con Kosik (1976), la esencia dei mundo se revela y se oculta en los fenómenos, así acumular todos los hechos no significa conocer la realidad. Concibiendo que la realidad es totalidad concreta, explicitaremos algunos datos, hechos y, en especial, aquellos que emanan de las vocês de los trabajadores y que, de alguna manera, se constituyen como manifestaciones de lo cotidiano de la colectividad obrera. Privilegiamos el discurso de los obreros porque creemos que ello - aunque no represente la realidad concreta de la vida en la fábrica contribuye para indicamos los rasgos físicos de las unidades productivas, adernas de expresar las perspectivas de sociedad, de trabajo y de educación/formación técnico-política que estaban contenidas en sus prácticas laborales. Junto con las fuentes secundarias y de los documentos oficiales de la empresa, hemos utilizado algunos

'De empresa asociada, a partir de 1993, Quirós ha entrado a formar parte dei grupo consolidado de Cortefiel, el cual, de acuerdo con la Memória de este mismo afio, posee un total de 213 tiendas que se encuentran abiertas bajo los rótulos comerciales de "Cortefiel", "Springfield", "Milano", "Women's Secret" y "Don Algodón". Destinadas a la venta ai dctallc, cuatro tiendas están ubicadas en Francia.tres en Portugal y las demás, en las principales ciudades espafiolas. Posee dos fábricas propias, una en Madrid, otra en Marruecos. 
periódicos de la época, entre ellos, Producción, portavoz de los obreros de Almacenes Quirós, los cuales contribuyen para el análisis de la compleja realidad en cuestión.

\title{
Madrid, 1936: colectividades obreras, productividad y concepto de "beneficio"
}

\author{
¡Madrid, Madrid! ¡que bien tu nombre suena! \\ rompeolas de todas las Españas \\ La tierra desgarra, el cielo truena, \\ tú sonríes con plomo en tus entrañas.
}

ANTONIO MACHADO

Después que las urnas anunciaran la victoria del Frente

Popular," una tentativa de golpe militar desencadena la guerra civil. Hasta 1939, en dos años y medio contra la sublevación franquicia, el ejército popular llegó a contar con 600 mil hombres contra 500 mil nacionalistas en armas (incluyéndose las fuerzas de Mussolini e Hitler). Madrid, sede del Gobierno Central, centro político, comercial y financiero del país, era la plaza que más interesaba conquistar a los militares, plaza donde era más difícil hacer triunfar la revolución popular. Se estiman unas 100 mil muertes en los campos de batalla, siendo 10 mil sólo en las luchas de Madrid en noviembre de 1936 (Jackson, 1990, p.458) - ciudad que sufrió bombardeo de las tropas nacionalistas a lo largo de la contienda. La victoria electoral representaba la conquista de 271 escaños parlamentarios frente a 142 conseguidos por los partidos de derecha. ${ }^{4}$

\footnotetext{
${ }^{2}$ Poema escrito en 7 de noviembre de 1936, poco antes de marcharse de Madrid para Valencia. En: Machado (1995, p.90)

${ }^{3}$ Coalición electoral de Izquierda Republicana, Unión Republicana, Partido Socialista Obrero Español (PSOE), Partido Comunista de España (PCE), Partido Obrero de Unificación Marxista (POUM), Partido Sindicalista, Unión General de los Trabajadores (UGT) y Federación Nacional de Juventudes Socialistas.

${ }^{4 \prime}(.$.$) de 13.553 .710$ electores, votaron 9.864 .783 , es decir $72 \%$ del censo, de los cuales 4.555 .410 lo hicieron a favor del citado Frente, a los que hay de sumar los 98.715 votos que obtuvo en Lugo, donde concurrió a la puga en unión de algunos partidos de centro, y los 125.714 del Partido Nacionalista Vasco" (Cabeza, 1978, p.328)
} 
Esta misma victoria también representaba la posibilidad del pueblo español de ir más allá en la lucha por la garantía de sus derechos de ciudadanía. Analizando el significado del golpe militar, García (1977, p.81) cree que este representaba una respuesta de las fuerzas de derecha "al amplio movimiento de incautación de tierras realizado después de las elecciones del 36, ya que para los campesinos el triunfo del frente popular era un triunfo suyo, de sus aspiraciones que rebasaban con mucho los cortos alcances pequeño-burgués de esa coalición" ${ }^{5}$ Entre 1936 y 1939, en medio a la lucha contra el fascismo, el pueblo intenta reorganizar la producción de su existencia bajo la perspectiva de los propios trabajadores. Las colectivizaciones obreras y campesinas ensayaron una nueva organización del trabajo y un nuevo sentido para la vida en todas las instancias de la sociedad, instaurando las transformaciones necesarias para garantizar el derecho de todos a la salud, educación, cultura... Para una población total de España de, aproximadamente, unas dieciséis millones de habitantes, siendo la población activa de cerca de cinco millones, se estima que hubo unas 1.400 colectividades agrícolas y varios centenares de colectivos industriales y de servicios que agrupaban unos dos millones de personas. En la zona del Centro, Mintz (1977, p.362) nos informa que hubo "240 colectivos agrícolas de $\mathrm{CNT}^{6}{ }^{6}$ con 23 mil familias, o sea, un mínimo de 67.992 personas, redondeando, a lo que habrá que agregar los colectivos de UGT, de por lo menos otro tanto, o sea, 176.000 en la agricultura". En la provincia de Madrid, se destacaban las colectividades campesinas de Coslada, Miraflores de la Sierra, Tielmes, Perales de Tajuña, Meco, Arganda y Fuentidueña.

\footnotetext{
${ }^{5}$ El Manifestó del Frente Popular, de 15 de enero de 1936, no se comprometía a promover transformaciones radicales en la estructura social. Además de amnistía a los presos y perseguidos políticos, prometía algunas reformas en las cuestiones relativas a la tierra y a la industria. La concepción mayoritaria era de una República que no sería "dirigida por motivos sociales o económicos de clase, sino un régimen de libertad democrática impulsionado por motivos de interés publico y progreso social". (Cabeza, 1978, p.349-350).

${ }^{6}$ Confederación Nacional de Trabajadores (CNT), sindicato de ideología anarquista, que, aunque no hubiera compuesto el Frente Popular, posteriormente asumió responsabilidades en el período del Goviemo Republicano.
} 
De acuerdo con los datos de Capella (1963, p.775), en Madrid, "al comenzar la Guerra española contra el marxismo (!), el total del Censo de Contribuyentes de la Cámara sumaba 12.906" y, en 1940, tras el término de la contienda, era de 12.603 el número de establecimientos industriales y comerciales en la ciudad. Sabemos que el Gobierno Republicano incautó la Sociedad Madrileña de Tranvías y los principales medios de comunicación de masas, pero, de hecho ¿cuál era la situación de la ciudad en relación a las colectivizaciones industriales? Sobre agosto de 1937, Franz Borkenau decía que "Madrid brinda mucho más que Barcelona la impresión de una ciudad en tiempos de guerra, pero mucho menos la de una ciudad en medio a una revolución social" (Mintz, 1977, p. 109). Aunque los ebanistas, zapateros, barberos y otros sindicados hayan colectivizados sus talleres y establecimientos, en realidad, comparando con el amplio movimiento colectivista de Cataluña, fueron pocas las realizaciones en Madrid. Bajo el slogan "No Pasarán", "Madrid estaba demasiado preocupado con la presencia cercana del frente para realizar desarrollos a amplia escala, aunque allí también se realizaron experiencias de carácter revolucionario" (García, 1977, p.106). Como uno de los principales centros de atención del alzamiento de los militares, es probablemente en las industrias de armamento para el ejército popular "donde la eficacia creadora de los obreros alcanzó las cotas más elevadas. Las necesidades bélicas hicieron que se desarrollara mucho la industria metalúrgica, la que a su vez favoreció el desarrollo de las industrias químicas" (idem, p.108). En Madrid, dos periódicos portavoces de los trabajadores atestiguan la existencia de industrias bélicas como la Sociedad Comercial de Hierros, situada en la calle Méndez Alvaro, y de Ferrobellum - Central Metalúrgica, las cuales fabricaban explosivos, ametralladoras, pistolas, máscaras y otros aparatos de guerra.

${ }^{7}$ Véase el periódico del Comité del Control Obrero de Unión Rádio. Madrid, 1937. ${ }^{8}$ Sobre la fábrica de materiales bélicos de Aranjuez, véase el periódico La espoleta de la victoria -portavoz de los trabajadores de experiencias industriales. Madrid, 1937. 
Además de la creatividad, a la población que vivía el racionamiento de víveres se le exigía un "esfuerzo de guerra". El periódico del Sindicato de Trabajadores de la Industria de Vestido orientaba, de manera contundente, a sus 17 mil afiliados en cuanto a las dos alternativas para favorecer la victoria: la primera era "enrolarse en el Ejército popular", la segunda, "trabajar con intensidad para producir mucho y barato". Además de estas, sólo había una tercera alternativa más: "evacuarse de Madrid, si en la capital no se hace nada por la guerra" (Vestido, 1937, n. 1). En Madrid, así como en Barcelona, también las industrias de producción de bienes de consumo eran transformadas en industria de guerra, es decir, para la guerra. De entre las fábricas y talleres colectivizados - cuyo proceso de producción fue puesto a favor de la victoria de la revolución popular - encontramos referencias a algunas vinculadas al sector textil y de confección: además de Almacenes Quirós, Talleres de Sederías Lyon (producción de tabardos), Confecciones Madrid (tabardos y canadienses), Fábrica de Gorras Gallega, Fábrica de Gorras Yusta, Manufacturas Valle, Fábrica de Gorras La Burgalesa, Manufactura Zagasti, Casa Pajares y la fábrica de tintorería y lavado Ideal.

Junto a una reestructuración profunda de la economía nacional, era preciso adaptar la producción a las necesidades de la revolución, a la que Almacenes Quirós sirve como un ejemplo del esfuerzo de los trabajadores madrileños para producir los bienes necesarios para la subsistencia de aquellos que luchaban contra el fascismo tanto en los frentes como en la retaguardia. Así, la obrera Carmen Prado, de esta colectividad, escribe a las trabajadoras de la fábrica: "Con mayor rendimiento en vuestro trabajo, trabajando más tiempo si es preciso, para que al Ejército del Pueblo no le falten prendas de abrigo, prendas interiores, y estén en condiciones de resistir todas las inclemencias del tiempo" (Producción, 20/1/1937). Otro obrero, en nombre de la victoria

\footnotetext{
${ }^{9}$ Además de evitar la muerte de niños y de mayores, la campaña para la evacuación de la población civil tenía como objetivo disminuir el problema de abastecimiento de una población tan voluminosa como Madrid.
} 
de las fuerzas populares, también reivindica de sus compañeros de trabajo la máxima productividad:

¡Más camisas...! ¡Más municiones...! ¡Más calzados...! Así nos dijeron los camaradas que heroicamente están luchando en los frentes de Guadalajara. Nosotros los camaradas que estuvimos en los frentes, hemos visto que es necesario trabajar sin descanso en la retaguardia, para que estos bravos muchachos, que están dando su vida para liberar el mundo del grupo fascista, no les falten vestidos (Producción, 5/4/1937).

En setiembre de 1937, un balance de las mercancías producidas en Almacenes Quirós indicaba: 75 mil jerseys de lana, 210 mil camisas y 16 mil calzoncillos. (Vestido, 15/9/1937). Las necesidades de reorganización de la producción llevaron a los trabajadores de Quirós al máximo de sus capacidades físicas: !70 horas de trabajo semanal!, elevando la fabricación de camisas, jerseys y de lana para suplir las necesidades de los frentes y de la retaguardia. De acuerdo con la voz de dos obreros:

Nuestras fábricas están produciendo hoy día al máximo que se le puede pedir; muchas compañeras (todos los sabéis) están haciendo jornadas de sesenta a setenta horas semanales, que supone una media de diez a doce hora diarias, durante la cual vienen a producirse de unas 1.000 a 1.200 camisas diarias, cifra que, contando con las dificultades del momento (...) sobrepasa con mucho a todas las logradas hasta ahora.

(...) por encima de las exigencias comerciales, están las necesidades de la guerra: las fábricas pueden y deben ser una ayuda eficaz para la Intendencia militar. ¡Y lo son! (...) en otra fábrica donde se fabricaban, por termino medio, cuatrocientos jerseys diarios, se llegan a fabricar mil, sin que tampoco importen las horas incesantes de trabajo. Y en la otra no se descansa un momento preparando lanas que han de servir para confeccionar a mano prendas de abrigo para nuestros milicianos (Producción, 20/5/1937).

La propia publicidad para aumentar la venta de las prendas producidas tenía como referencia la posibilidad de la victoria: "TRABAJADORES: comprando en ALMACENES QUIRÓS Colectividad Obrera, favorecéis a numerosos compañeros y contribuiréis al triunfo de la revolución española". Y para concretar aún más su 
compromiso con el ejército popular, los obreros de Quirós eligieron a los soldados de 11 División Lister para apadrinarlos, satisfaciendo las necesidades de vestido del batallón instalado en un pueblo de Guadalajara. Los compromisos con la revolución también estaban en compartir con los compañeros las tareas tanto en los frentes de batalla contra el enemigo como en los frentes del trabajo fabril, así en Quirós, "(••) en algunos momentos el 65 por 100 de nuestros trabajadores, se encontraba en las trincheras, defendiendo con las armas los ideales de justicia que todos anhelamos" (Producción, 5/2/1937).

Así como en otras fábricas y talleres, en la Asociación Colectiva Almacenes Quirós - el principal objetivo era la producción de la libertad de los trabajadores del yugo del capital, lo que tenía como condición sino qua non la victoria popular. Si de un lado el trabajo era un elemento fundamental en la lucha contra el fascismo, de otro, los obreros fueron más allá en sus perspectivas de clase. Al contrario de la lógica capitalista de producción, la ganancia no sería el resultado de la explotación obtenida con la máxima productividad del trabajo - como se les había impuesto por los antiguos propietarios desde el final del siglo pasado. El lucro no tendría como consecuencia la satisfacción inmediata de este o de aquél trabajador, sino sería el resultado del esfuerzo del colectivo obrero para la victoria de la revolución popular. El beneficio principal e inmediato de la colectividad seria garantizar los puestos de trabajo y los salarios para la supervivencia de los obreros, y... quizás, disfrutar plenamente de los frutos del trabajo en la futura sociedad que deseaban y que intentaban construir. Para ilustrar la perspectiva de "beneficio" que ahora pasa a ser el móvil del trabajo, reproducimos parte de un editorial de Producción, en el cual el Consejo Obrero criticaba la lógica del capitalista,

(...) que cree producir riqueza engrosando su fortuna personal y que lo nacía creer a los demás que la patria será más rica cuanto mayor sea su cuenta corriente personal y que todos los españoles debemos sentirnos orgullosos de las joyas que lucía su señora en las fiestas palaciegas. (...) Para el porvenir debemos desechar de nuestro espíritu y de nuestro vocabulario la palabra "beneficios" en el sentido estrecho de "pesetas a 
repartir", pues si esas pesetas que antes se guardaba el patrono capitalista ahora nos las repartiéramos nosotros, en primer lugar tocaríamos a muy poco y no habríamos hecho más que quitar de su puesto a un burgués para instalar en él quinientos o mil.

No, esos "beneficios" no deben interesarnos; debemos aspirar a otra clase de beneficios más beneficiosos. El principal beneficio de la colectivización de las industrias será asegurar la continuidad del trabajo y la estabilidad del trabajo. La implantación del trabajo como único medio legal de vida, traerá como consecuencia la intensificación de la producción y el reparto equitativo de la riqueza o medios de producción a través de la totalidad del territorio español (...).

Del esfuerzo común y simultáneo de todos los brazos, de todos los cerebros, de todos los corazones españoles, surgirá la grandiosa economía nacional, de la que tanto hablaron y por la que tan poco hicieron los que no conocían más interés que su interés personal, ni más España que la que representaba la clase a que ellos pertenecieron. (Producción, 5/3/1937).

\section{Consejo Obrero: hombres y mujeres en la organización del trabajo}

La revolución española convivió con dos formas de gestión de los trabajadores: la primera era el Control Obrero, la cual ocurría en las pequeñas y medianas fábricas, en las que el propietario no había huido. El no podía tomar ninguna decisión sin consulta o autorización del comité de trabajadores. La segunda era el Consejo Obrero; como en el caso de ACTAQ., era un tipo de organización en el interior de la fábrica que se constituía en una situación en que desaparecía la figura del antiguo propietario, y los obreros iban, en la práctica, preparándose para ejercer todas las tareas de concepción y ejecución. Como órgano coordinador del trabajo fabril el Consejo era formado por tantos miembros como secciones que componen la colectividad. Cada una de las secciones elegían su representante y el cargo de presidente lo nombraría la colectividad en votación general. La defensa de los intereses colectivos sería el fundamento de la vida en colectividad; el texto final del reglamento fue publicado en el periódico Producción - el 
cual intentamos resumir. La asociación, a la cual pertenecían todos los compañeros que trabajaban en la empresa en la fecha de su incautación, tenía "como finalidad principal la explotación comercial de los medios de producción y venta de que dispone, con el fin de contribuir al engrandecimiento de la economía nacional y en interés de sus asociados". Aquellos que habían ingresado después de esta fecha sólo pasarían a integrar la colectividad pasado un año de trabajo. Los hijos y hermanos de los trabajadores tenían preferencia para ocupar las plazas vacantes, siempre y cuando estuviesen sindicados, además de aptos para desempeñar el puesto a ocupar. Junto con el Consejo Obrero se crearía "una Comisión revisora de cuentas, compuesta por un miembro elegido en cada sección", cuyo objetivo era vigilar la administración general de la colectividad. O sea, esta comisión tenía el poder de controlar la gestión del Consejo Obrero, el cual debería semestralmente dar cuenta de los resultados de la producción, poniendo sus cargos a disposición de la asamblea general. Desde esta perspectiva, Antonio Lagar decía a los demás trabajadores que el consejo podía equivocarse, pero jamás podía ser visto como la continuación de los señores Quirós, pues si bien a aquéllos no podían quitarles de los puestos de dirección, a éste si podían hacerlo (Producción, 20/1/1937).

Los artículos de Producción relativos al año de 1937 indican la existencia de 500 trabajadores en la colectividad, otras veces hacen referencia a 400 de ambos sexos; en otro artículo de setiembre de 1937 habla en "trescientos compañeros". No estamos seguros de los números exactos en cada uno de los diversos momentos de la guerra civil, pero sabemos que ellos varían de acuerdo con la solicitud del Gobierno Republicano para que los trabajadores ingresen en los frentes de defensa de Madrid. Sin embargo, sabemos que históricamente las mujeres han sido la fuerza de trabajo predominante en la industria textil; en Vestido, el periódico portavoz del Sindicato de Trabajadores de la Industria de Vestido (con 17 mil afiliados) es posible observar que los artículos son, 
en su mayoría dirigidos a las mujeres trabajadoras, y son ellas las que tienen la palabra en los informes sobre los talleres y fábricas colectivizadas en Madrid. Es curioso observar que, aunque en las fábricas de la colectividad Almacenes Quirós el sexo femenino representara la casi totalidad de personal - lo que es posible verificar a través de las fotos publicadas en el periódico - son los hombres quiénes, en general, ocupan los cargos de liderazgo técnica y política. Si bien, la participación política de las mujeres no correspondiera a su presencia numérica, ellas estaban representadas en el Consejo Obrero, aunque sólo en Camisería y Tricotaje. De entre los diez trabajadores que participaron de la primera gestión sólo tres eran mujeres; también en la Comisión Revisora de Cuentas, compuesta por cinco miembros, figura la presencia de una obrera representante por Tricotaje. Como intento de aumentar la participación femenina en lo cotidiano fabril, es posible notar la constante preocupación en promover la emancipación de la mujer y la igualdad de derechos en la nueva sociedad que se construía. De acuerdo con la obrera Carmen Sardina, las mujeres iban a

(...) dejar de ser el instrumento sexual y de cocina a que nos tenía postergadas el régimen capitalista para pasar a ser un tornillo más de la máquina de construcción de la nueva España. (...) en el nuevo tenemos que ser no solamente la compañera que comparta la felicidad con el compañero, sino compartir el trabajo, para que al mismo tiempo que ayudamos con nuestro esfuerzo a vivir con alegría y hacer del trabajo una satisfacción, que tanto soñamos las obreras y que hoy están ganando los obreros en los frentes.(...) Compañeras: por nuestra pronta emancipación, derrotemos desde nuestras máquinas al fascismo produciendo más y mejor (Producción, 20/2/1937).

Además de una herramienta de lucha contra el fascismo, el trabajo era considerado un elemento fundamental del proceso de liberación de la mujer, la cual, junto con los hombres, construiría una sociedad no opresora, libre del yugo del capital. Teniendo la misma capacidad de trabajo, hombres y mujeres eran indistintamente productores de los bienes materiales y de los bienes culturales necesarios para la construcción de una sociedad igualitaria. La importancia del nuevo papel 
que juega la mujer en el proceso productivo está muy bien expresado en una portada del periódico Producción. Bajo el dibujo de una mujer semidesnuda entre una engrenaje y varias chimeneas de fábrica, se lee: "¡MUJER! A tu manos se encomiendan el comercio y la industria. ¡Defiéndelos!"

\section{Tricotaje - aprender y enseñar desde el "corazón de la fábrica"}

Además de intentar describir el proceso productivo de Almacenes Quirós, nuestro principal objetivo es explicitar algunos de los conocimientos que tenían los actores de la colectividad obrera sobre las tareas fabriles y sobre sus retos tecnológicos. Para esto elegimos el escenario de Tricotaje, una de las secciones de Almacenes Quirós y uno de los muchos espacios donde se manifestaba la síntesis del saber científico y del saber práctico adquirido/producido por los trabajadores "a pie-de-la-fábrica". De ahí que merezca la pena reproducir, a las veces, extensas explicaciones de los obreros sobre las especificidades de la maquinaria y de la línea de producción.

Tricotaje era la sección de la Colectividad Almacenes Quirós donde se fabricaba el género de punto, en especial artículos de lana. Un supuesto "periodista" con las iniciales L.R.C., describe las instalaciones de Tricotaje como "un edificio de nueva construcción de líneas esbeltas, en el castizo barrio de Chamberí, sobre los terrenos conocidos por el Merendero del Tío Merege". El objetivo de la visita del periodista había sido el de conocer las dependencias de la empresa; y para dársela a conocer a sus lectores, reproducía en su artículo la explicación del responsable de la fábrica que le había acompañado:

Planta baja - Depósito de materias, hilatura en grandes madejas: Lana Australia, Lana, Novedades, Algodón y otras materias.

\footnotetext{
${ }^{10}$ Las secciones de ACTAQ eran: Camisería (confección y plancha); Tricotaje (textil y confección); Hilosa, Almacén, Sucursales (Romanones, Precidados, Fuencarral, Luchana, Montera y Pi y Margal); Publicidad, Taller Mecánico y Administración.
} 
Planta primera - Maquinaria, muchas máquinas; mire, una de las varias devanadoras; esas grandes madejas que le indiqué, se colocan sobre estos discos, transformándose en carretes, conos, bobinas; esta otra nos prepara los conos que se utilizan en estas máquinas, mire: en esta sección todo son Tricotosas; estas máquinas son muy complicadas, es en donde fabricamos los trozos de tejido para confeccionar estas blusas y chaquetitas que usted ha contemplado en una de nuestras exposicione (Producción, 5/5/1937).

\section{¿Cómo funcionaba la máquina Tricotosa "Ban"? La explicación} nos la da un obrero llamado Dionisio Rebollo, quien nos advierte que, aunque no sea un técnico tiene una "pequeña idea", ya que ha trabajado durante mucho años en la casa Quirós. Es importante observar que el obrero describe todos los detalles de las diversas operaciones, aún desconociendo la ciencia que la máquina incorpora:

Según el tejido que se quiera hacer, se colocan tantas bobinas como sean necesarias con sus colores correspondientes. Se coloca la bobina encima de un soporte, donde sobresale un gancho que es donde se coloca la bobina, pasando por unos "tensa-hilos", que funciona sobre la plancha de la máquina; en dicha plancha van seleccionadas las agujas que fabrican el tejido. Para fabricar el tejido hay dos filas de agujas que hacen un total de 1.200, que al pasar los carros que llevan los "porta-hilos" pasan sobre las agujas confeccionando el tejido. El tejido que se fabrica va sujeto por un tensador, el cual lleva unas pesas para graduar la tensión con objeto de que no se suelte de las agujas; esta máquina tiene un reloj contador, el cual tiene unos dientes que al dar la vuelta completa se mueve un diente, y al llegar a las vueltas correspondientes a un jersey dispara automáticamente y vuelve a empezar otro.

Para poner en marcha esta máquina tiene una manivela que es la que hace dar a los carros su movimiento de vaivén, y para parar es suficiente tirar un cordón que le hace parar rápidamente. También se suele parar la máquina cuando un hilo lleve el nudo más insignificante, el cual tropieza en el "tensa-hilos" y dispara automáticamente. Encima de la plancha van unas barras que llevan 8 "porta-hilos" (4 grandes y 4 pequeños). El funcionamiento de dicha máquina consiste en una "cadena" automática, la cual hace funcionar los movimientos que se deseen para fabricar un tejido, por ejemplo: Funcionan dos "porta-hilos" grandes, y uno de los movimientos le hace coger uno grande y uno pequeño y de esta forma, haciendo el cambio de hilos, sale el tejido en varios colores y funcionando solamente dos es cuando sale el tejido de un color. Lo principal de la máquina "Tricotosa" consiste en dicha cadena que es la que necesita para hacer toda clase de cambios y dibujos (Producción, 20/5/1937). 
La clase sobre la máquina Tricotosa Ban dictada por el obrero Dionisio Rebollo invita a los expertos en "arqueología industrial" a reconstituir las características de la producción textil en el segundo tercio de este siglo. (¿Qué sería del trabajo de los intelectuales sin el trabajo de aquellos que cotidianamente hacen el proceso productivo?). Lo más significativo es que los conocimientos de Dionisio no se constituyen como conocimientos privados, como conocimientos suyos, del "ingeniero" o del "técnico", más bien debían ser de toda la colectividad - propiedad colectiva de todos los trabajadores de Almacenes Quirós. Dionisio termina diciendo:

Sería muy interesante para todos los obreros de la colectividad conocer el manejo de esta máquina, tratándose de una cosa tan bonita y curiosa, pues no creo tendrían inconvenientes los obreros de las mismas en dedicar fuera de las horas de trabajo a los demás compañeros unas charlas y conferencias de la misma, para que se dieran cuenta de la importancia que tiene la máquina "Tricotosa" (Producción, 20/5/1937).

Para los trabajadores que a lo largo de la historia de la empresa habían sido despojados de la posibilidad de acceso a los 'secretos' tecnológicos de la producción, la práctica era, para la grande mayoría, la única fuente de conocimiento. Ahora, el saber que era socialmente producido en el proceso de trabajo, no debería ser propiedad de este o de aquel trabajador, sino pertenecer y ser distribuido al colectivo fabril. Una de las herramientas de socialización de saberes era el periódico Producción, en cuyos artículos escritos ñor los obreros fue posible tener la información de que el taller de Tricctaje era compuesta de máquinas de tejer, urdidoras, cardadoras y de planchar. Entre ellas estaban las llamadas "Rachel" que funcionaban con un operador el turno de la mañana y otro para el de la tarde. El obrero Aristides, que trabajaba en esta fábrica nos explica que en la calidad de la producción influían "el estado de la lana, el estar bien tensado el rollo, la nivelación de pesos, el estado general de la máquina, etc." (Producción, 20/2/1937). Las máquinas "Rachel" en general hacían el tejido de un prenda en tres horas, pero llegó a alcanzar el récord de 55 minutos por algunas obreras "stajanovistas" (estilo de producción del cual hablaremos adelante). 
En Tricotaje también se hallaba el "taller de confección". El proceso de producción, de acuerdo con la explicación también muy detallada que fue suministrada al supuesto periodista L.R.C., es el que intentamos sintetizar: corte del tejido; preparación para el montaje; costura; corte del sobrante; paso por el transportador (?); pespunte de seguridad; colocación de los adornos; remate de la prenda; control de la calidad; planchado a vapor y embalaje (papel celofán-cajas). Allí, la casi totalidad de las máquinas eran de procedencia extranjera $\mathrm{y}$, con el bloqueo económico impuesto a la España revolucionaria, se planteó el problema del recambio de piezas imprescindibles que no se hallaban en otros talleres de confección de Madrid y tampoco en los de Barcelona. Así las principales máquinas se iban parando, amenazando el futuro de las 200 obreras de Tricotaje. Algunos de estos problemas eran resueltos con la voluntad y la habilidad de los obreros de Quirós, que con creatividad conseguían fabricar/reproducir las piezas originales necesarias para mantener la productividad. El trabajo en la fábrica y los retos de la guerra los desafiaban y los invitaban a una nueva calificación.

Sabemos que no es posible hablar de calificación sin hablar de división de trabajo; en el interior de la organización capitalista la posibilidad de acceso al saber socialmente producido y la amplitud de sus fundamentos histórico-científico han tenido como presupuesto la jerarquía en la producción. En Almacenes Quirós, así como en otras fábricas, la revolución popular permitió otra lógica para el proceso productivo: permitió que los obreros sistematizasen y ampliasen sus saberes más allá de lo permitido por los antiguos propietarios y por su condición de clase. Como había dicho Gramsci (1982, p.8), en el mundo moderno, la educación técnica, orgánicamente articulada al trabajo industrial, aún al más primitivo y descalificado, debe constituir la base del nuevo tipo de intelectual. Al aprender y enseñar en el "corazón de la fábrica", los obreros daban el primer paso hacia una formación técnicohumanista $y$, sin embargo, el conocimiento práctico inmediato - aunque expresión de una determinada teoría - por sí sólo no era suficiente para responder a las necesidades de la producción y tampoco a las necesidades de la omnilateralidad y de la multidimensionalidad humana. 


\section{La fábrica-escuela: del "técnico" a la capacitación de todos los obreros}

La guerra civil y con ello, la socialización de la producción, planteaban numerosos problemas y desafíos; para el Consejo Obrero el más importante era el problema de la moral del trabajador. La práctica cotidiana les indicaba que en la mayoría de los casos, el trabajador al hacerse cargo de los medios de producción no estaba suficientemente preparado técnica y políticamente para enfrentar el nuevo lugar que ocupaba en el proceso productivo. La profunda revolución no significaba sólo el paso de los elementos de producción de las manos del capital a las del trabajador; también exigía un cambio radical de su mentalidad, o sea, de su relación con su propio trabajo. La transformación social no se haría sólo a partir de la lucha de clases propiamente dicha, sino fundamentalmente en la búsqueda de otro significado para la producción, instaurando una nueva cultura del trabajo. Pero, sabemos que esto sería un largo proceso, pues la realidad es que eran "incluso muy pocos los que han comprendido plenamente que los instrumentos de trabajo, las máquinas, las herramientas las grandes factorías, son materia inerte y fría, a las que sólo puede infundir vida el espíritu, el entusiasmo y el cariño del hombre que las maneja" (Producción, 20/1/1937).

Con la huida de los antiguos propietarios, huyeron también los técnicos que ocupaban los puestos de mando en Almacenes Quirós. "Al desaparecer la gerencia hubo también la necesidad de desplazar de la industrias a los elementos técnicos, por resultar desafectos al régimen." (Producción, 5/4/1937). Pero no todos los técnicos podían ser considerados enemigos de la colectivización por el hecho de haber participado como intermediarios de los capitalistas; a ellos pertenecían algunos de los secretos de la fábrica y por lo tanto era necesario tornarlos aliados. Antonio Lagar decía que "nosotros nos distanciamos del obrero técnico, cuando tenemos que ver en él al hermano mayor que nos guíe y ayude en nuestra rápida emancipación." (Producción, 20/2/1937). Sin embargo, ahora, los conocimientos no serían sólo de propiedad de lo 
técnicos, más bien era necesario que todos los obreros de la colectividad se tornasen obreros-técnicos. A los trabajadores que históricamente estuvieron relegados a las tareas de ejecución, ahora les cabría la gestión de la producción y, para intentar dar cuenta de su nueva tarea, llevaban como bagaje los conocimientos prácticos adquiridos "a pie-de-lafábrica".

Según Gramsci (1982, p.7-8), todos los hombre son intelectuales, pero en nuestra sociedad, no todos desempeñan la función de intelectuales. En Almacenes Quirós, aquellos que a lo largo de la historia de la empresa fueron impedidos de crear y recrear plenamente su trabajo, ahora se ponían delante de la posibilidad de transformarse en los nuevos intelectuales de nuevo tipo, o sea, transformarse en los gobernantes de sí y de su trabajo. Para esto era preciso articular conocimiento práctico y conocimiento científico, articular técnica y ciencia de acuerdo con las necesidades político-sociales de su proyecto de clase. Desde esta perspectiva, Reinoso, del Consejo Obrero, escribía a los demás compañeros de la colectividad:

Dice Lenin: "Toda cocinera debe saber administrar el Estado" (...) "debemos aspirar en la sociedad futura, a que cada ciudadano, cada obrero esté capacitado para desempeñar esta función". (...) Ese que nos sugiere la frase de Lenin: El de la capacitación de todos sin distinción de sexos ni de puestos en la producción.

Entonces cuando esta capacitación sea un hecho, sin más diferencias que los dones naturales (que a la larga también desaparecerán), entonces el problema de la responsabilidad de los puestos de mando se habrá simplificado. La comprensión entre el camarada responsable y sus colaboradores hará mas fácil y más eficaz la tarea de la producción (Producción, 5/2/1937).

Contrariando la lógica de la organización capitalista de producción, la perspectiva de formación de 'técnicos' no era restrictiva a los miembros del Consejo, sino era un desafío a todos los obreros de la colectividad. El proyecto educativo era parte integrante del proyecto de hombre y de sociedad que la revolución popular empezaba a ensayar. Para esto, desde ya, cada un de los obrero debería dejar de ser un apéndice de la máquina, transformándose en obrero-técnico: 
Es preciso acabar con el obrero autómata, sin iniciativas ni curiosidad por su profesión. Es necesario que el obrero conozca a fondo sus máquinas para que esta compenetración de brazo y herramienta ayude a crear el amor del trabajador por su obra; ayude a instaurar una nueva moral del trabajo con obligación social y, por último, contribuya a hacer desaparecer el odioso concepto de trabajo como castigo, que tanto ha influido en el desorden social que hemos tenido que soportar durante la era capitalista.

El trabajo era el arma fundamental en la construcción de la sociedad socialista, así era preciso aumentar y mejorar todas las formas de producción, pero esto, bajo un nuevo supuesto: el fin de la dicotomía entre hacer y pensar el mundo fabril. La tarea de los nuevos trabajadores colectivos sería aprender a utilizar los últimos adelantos y crear nuevas técnicas, y además hacer "que el alma de la máquina sea más perfecta; que el obrero, siendo un verdadero técnico, se sirva de ella al máximo de rendimiento" (idem). Como había dicho Luis Marcos, de la Juventud Socialista Unificada (JSU), "es en la técnica donde se debe hacer la revolución, puesto que nosotros necesitamos para la nueva era de trabajo una nueva técnica" (Producción, 20/3/1937). Si de un lado el trabajo era considerado como una de las llaves para garantizar la victoria del ejército popular y construir la nueva sociedad, de otro, la educación obrera también era una de las condiciones para dicho objetivo. En un artículo para Producción, un obrero habla de la situación de "ignorancia" en que se encuentra la clase obrera, y en especial los obreros de Almacenes Quirós. Bajo el título "Cultura y Trabajo", denuncia a los capitalistas, considerando que la educación era para ellos un instrumento de dominación de una clase sobre otra:

Es evidente que nuestra falta de conocimientos generales, o lo que es lo mismo, la incultura que el capitalismo había impuesto como un tormento más al trabajador, la clase privilegiada hizo de esta ignorancia su más firme pedestal de combate, por que así vedado para el obrero el terreno de la cultura, ellos se sentían más afianzados en su "cetro" de casta superior elegida. (...) Nosotros hemos de comprender bien que nuestra Colectividad se afianzará cada día más, en la medida en que nuestras inteligencias se vayan despejando. En nuestras fábricas tenemos compañeras analfabetas, y otros que casi lo son también, y que es lo que pueden exhibir como herencia de la clase explotada (Producción, $5 / 10 / 1937)$. 
En la guerra civil, la educación tuvo un importante papel: la bandera de lucha era combatir el analfabetismo y promover la emancipación cultural de los trabajadores y de la población en general. El Sindicato de los Trabajadores del Vestido advertía a los consejos obreros, a los comités de control, a los comisarios sindicales y a los demás responsables de taller y fábrica: "(••) el deber que tienen de ayudar a nuestro Comité Central en su lucha por la cultura. Para ello deben cuidar que todo compañero o compañera analfabeto acuda a las escuelas que el Ministerio de Instrucción Pública ha puesto a disposición de nuestro Sindicato" (Vestido, 15/3/1937). Además de las muchas iniciativas del Ministerio de Instrucción, tales como los Institutos Obreros, se crearon verdaderas escuelas en el interior de los espacios de trabajo. Cada fábrica organizaba sus clases de acuerdo con las necesidades inmediatas de sus trabajadores. La industria bélica Ferrobellun, preocupada por la educación primaria y por la capacitación técnica de sus obreros, organizó "una completísima escuela" dividida en 3 secciones: la primera era destinada para analfabetos y semianalfabetos, donde ejercitaban, sobre todo, la lectura y escritura; la segunda, para "desarrollar con amplitud dichas dos materias y la aritmética. Y la tercera, en fin, para estudios tales como la geometría, geografía, gramática, etc." Se daban clases después de la jornada de trabajo: todos los días de nueve a diez y media de la noche. Y, con la mira de atender a las necesidades de acceso a la cultura general, todos los domingos se promovían conferencias sociales y profesionales (Ferrobellum, 14/7/1937). Lo mismo pasaba en Comercial de Hierros, en que un grupo de trabajadores tomó la iniciativa de organizar una escuela técnico-profesional, cuyas clases se daban en la fábrica misma. Las asignaturas, tales como dibujo lineal, geometría y aritmética, eran dictadas por los técnicos de la Colectividad. Así, el periódico Hoy, portavoz de la colectividad, anunciaba con orgullo que

Según el censo de la población de España, de los 750.896 habitantes de Madrid, 161.135 no sabian leer y 8.165 sólo sabian lecr. 
Nuestra fábrica tiene ya también su escuela, sus alumnos y sus profesores. Una escuela muy sencilla, muy modesta, destinada a darnos aquellos conocimientos de instrucción primaria y profesional que puedan ser base de otros posibles y más extendidos estudios. Hasta ella han llegado muchos obreros, cansados en la jornada, pero animosos ante la nueva y jubilosa perspectiva de conocer lo ignorado. (...) Ya tenemos pues, nuestro filón de cultura. Nadie en la fábrica deberá, dentro de poco, llamarse analfabeto (Hoy, set. 1937).

También en Almacenes Quirós, la socialización de los medios de producción imponía que los nuevos propietarios fueran más allá de un saber práctico y fragmentado, exigiéndoles el acceso a los fundamentos del mundo del trabajo y del mundo en sociedad. Creían que la organización de cursos elementales (por de pronto) podría ayudar a aumentar la capacidad creadora y productora de los obreros. Pero, ¿quiénes serian los maestros responsables para tantos alumnos?

A los compañeros capacitados les exhortamos para que ofrezcan la colaboración. A los compañeros deseosos de aumentar sus conocimientos les recomendamos que no duden en dedicar algunas horas semanales a esta tarea. Enviar a la Redacción (estudio de propaganda) por escrito vuestros conocimientos para enseñar o para aprender (...) (Producción, 5/2/1937).

A lo largo de sus vidas, muy pocos habían tenido acceso al conocimiento universal sistematizado, muy pocos habían tenido el privilegio de frecuentar una escuela. Aunque no obtuvieran un discurso que reconociera la legitimidad del 'que-hacer' como fuente primera del acto de conocer, y que en el saber práctico - aunque fragmentado -está contenida una determinada teoría y una determinada concepción de vida y de mundo, los trabajadores reconocían que el primero principio para su emancipación cultural era la socialización y distribución del conocimiento producido/adquirido por ellos mismos tanto en la propia fábrica de Quirós como en las demás instancias sociales. Reconocían que, además de propietarios de la fábrica, eran propietarios de saber. Así,

Varios compañeros nos han ofrecido su colaboración para la formación de cursos de perfeccionamiento y capacitación. Estos compañeros están 
dispuestos a dedicar los domingos por la mañana a los compañeros y compañeras que desean adquirir o ampliar sus conocimientos. Son estos los compañeros: Juan José, que explicará Contabilidad; Valls (ingeniero), que explicará Aritmética, Geometría y técnica industrial; Mariano, que explicará Gramática; Reinoso, que explicará Francés y Dibujo (Producción, 5/3/1937).

Así de lunes a sábados, ofrecían clases de geometría, gramática y ortografía, de siete y media a nueve de la noche. Después de una larga jornada de trabajo, los obreros iban para la escuela improvisada; sentarse en los bancos escolares era para ellos un privilegio, además de una posibilidad de tornar real el sueño de construir una nueva lógica para la organización del trabajo y de la vida en sociedad. Pero, la escuela no sería el único espacio para ampliar sus conocimientos a cerca de la realidad; la organización de una biblioteca era otra alternativa para propiciar el deseo de acceso a la cultura.

En la sala de lectura de la biblioteca, se organizaron "lecturas colectivas comentadas y charlas sobre las mismas, así como conferencias y proyección de películas" (Producción, 20/2/1937). Los obreros podrían frecuentarla fuera de las horas de trabajo y los domingos por la mañana. Estos libros eran obtenidos a través de donativos; en marzo de 1937 habían obtenido 300 libros, y en setiembre de 37 el balance del bibliotecario Luis Andrados indicaba 568 libros que correspondían: "500 libros a la sección de literatura general (novelas, etc.); 6 libros de la sección de Poesías; 37 libros de la sección de Estudios; 7 libros de la sección de Político-Social" (Producción, 15/9/1937). Para estimular el hábito de lectura y así ampliar la cultura obrera, la Biblioteca promovió el Primer Concurso Cultural, cuyo objetivo era "conocer a los autores de distintas producciones literarias y musicales, de pintura y algunos inventos". Los premios a los ganadores atestiguan el espíritu educativo de la iniciativa: Don Quijote de La Mancha, de Cervantes; un álbum de reproducción de los cuadros de Velazquez; obras completas de José María Gabriel y Galán (Producción, 5/11/37). El teatro era también una forma de educación; el Socorro Rojo Internacional organizó el grupo 
Los Marinos de Komosol, compuesto por varios obreros-actores, que llegaron a presentar Los Semidioses, de Federico Oliver. El grupo después se fusionó a Curva, escuela proletaria de arte escénico que estaba a cargo de Zesar D'Rio, el cual decía de la importancia del libro, del arte como armas para conquistar la consciencia universal (Producción, 20/7/1937).

La educación no sólo sería técnica, sino también fundamentalmente política. Era necesario no una formación estrecha, utilitarista, inmediata para el mundo del trabajo, sino una formación integral, general y amplia. El proceso de formación de los nuevos dirigentes de la producción contemplaba las diferentes instancias del acto de conocer: desde la máquina a los bancos escolares, pasando por la vida artística y cultural. El punto de llegada sería una nueva manera de hacer y concebir el trabajo y el mundo en su entorno, contribuyendo para que en el futuro pudieran tornase intelectuales de nuevo tipo, es decir, sujetos productores y creadores de historia, capaces de tornar la ciencia y la técnica en una expresión de su proyecto de clase.

\section{Stajanovismo, participación y compromiso político}

En "La voz amiga de Stajanov", el periódico Ferrobellum reproduce "la vibrante carta que Alexis Stajanov, el obrero sagaz creador de un sistema de trabajo ya famoso, ha dirigido a Dolores Ibárruri". Decía él, orgulloso:

Me siento dichoso al saber que los métodos de trabajo socialista, tan ampliamente extendidos en mí país, han encontrado eco en el pueblo español... al aumentar el rendimiento de vuestro trabajo, estáis ayudando a la victoria. ¡Más cartuchos!; Proporcionádselo a los hábiles tiradores cuyas balas van a limpiar la tierra de España de asesinos fascistas (Ferrobellum, 29/1/1937).

\footnotetext{
${ }^{12} \mathrm{E} 1$ nombre del grupo teatral era en homenaje a Komosol - "buque de carga soviético que durante la guerra civil española hizo diversas viajes a la España republicana transportando material de guerra y hombres, y que fue hundido por la Marina nacionalista, posiblemente por el crucero 'Canarias' a finales de 1936. Con motivo de tal hundimiento, las Juventudes Socialistas Unificadas de Madrid, seguiendo instrucciones de su ejecutiva nacional, organizaron uns cuestación para recaudar fondos con los que la URSS pudiera construir otro buque semejante que llevase el mismo mombre." (Cabeza, 1978, p.454).
} 
El modelo stajanovista de producción, que se caracterizó como una versión socialista del taylorismo y que, de acuerdo con lo que atestigua la carta de Stajanov a Dolores Ibárruri, había sido ampliamente divulgado en España como una alternativa para garantizar la máxima productividad. Aunque pretendiera abolir el "gorila domesticado", los métodos de fabricación reproducían los principios elementales de Taylor; si de un lado el obrero no debía ser "una mano controlada por un cerebro distante" (Braverman) - como requería la administración capitalista - por otro la ingeniería de tiempos y métodos garantizaba la eficiencia del trabajo a través del control de un cuerpo, cuyos movimientos habían sido previamente estudiados y programados. En verdad, las prácticas stajanovistas mantenían el "cronómetro de parada automática" como paradigma de la producción, manteniendo en el taller la dicotomía entre músculos y cerebro. En las colectividades obreras, Stajanov representaba el símbolo de la dedicación al trabajo; en los talleres de Confecciones Madrid era él quien inspiraba el trabajo arduo de tantas mujeres: "En nuestro taller que hace con 15 máquinas 561 canadienses y 56 tabardos, que hacen un total de 617 prendas, siendo las mejores stajanovistas María Luna, Irene Nieto y Matilde Gonzales (...)" (Vestido, 15/3/1937). En la fábrica de Comercial de Hierros, ser un 'stajanovista' también significaba ser un bueno trabajador, aquel que daba el máximo de su rendimiento, pero también estaba comprometido con los objetivos sociales de la industria, era en definitiva el trabajador que producía día e noche "sin tasa, sin jornada fija; es decir, cumpliendo todos verdaderos 'stajanovistas', fomentando una moral de guerra" (Hoy, ago. 1937).

Además de un método de producción fundamentado en la organización científica del trabajo, el stajanovismo se constituyó como un movimiento para revolucionar las industrias tras la revolución socialista en Rusia y ahora en España, después que los trabajadores ocuparon las

${ }^{13}$ Dolores Ibárruri, militante del Partido Comunista de España que ocupó el cargo de ministra en el Govierno Republicano; conocida como "La Pasionaria". 
industrias en 1936. El objetivo era poner la técnica al servicio de los intereses de los trabajadores y no más al servicio del capital - al revés de "time is money", la máxima productividad tendría como lógica la distribución igualitaria de los frutos del trabajo, satisfaciendo las necesidades básicas del hombre.

El movimiento stajanovista está llamando a operar una revolución en nuestra industria: $\mathrm{y}$ es precisamente por esto por lo que el movimiento stajanovista es de esencia profundamente revolucionario. Este movimiento tiene, ante todo, por base el mejoramiento radical de la situación material de los obreros. La vida llega a ser mejor y más alegre, y cuando se vive alegremente el trabajo marcha bien. (...).

Otra de las causas del movimiento stajanovista es la ausencia de la explotación. Nosotros tenemos que darnos cuenta de que ahora trabajamos (...) para nosotros mismos, para nuestra causa, para nuestra España, donde están en el poder los mejores hombres de la clase obrera. Es por esto por lo que en nuestro país el trabajo tiene una verdadera significación social (Producción, 20/3/1937).

No cabe duda que el trabajo ganaba otro significado en el interior de las colectividades obreras. Aunque la organización stajanovista de la producción no posibilitara la articulación trabajo manual y trabajo intelectual, los cambios tecnológicos exigían una nueva calificación de los trabajadores: era preciso aprender a ser un stajanovista, es decir, dominar el propio cuerpo para dominar la maquinaria, poniéndola a la disposición de los intereses colectivos de la sociedad. La nueva calificación no era meramente técnica, sino también política: además de controlar el cuerpo, aprender a vivir en colectividad era aprender a compartir los frutos del trabajo, y el proprio trabajo.

Creo que el trabajo en colectividad será la forma de trabajo en el futuro, ya que este ha de ser la base de una colaboración conjunta y entusiasta, en la que cada uno dará de sí todo el rendimiento de que sea capaz, sin escatimaciones, sin regateo de esfuerzos; pues sabe que su actividad es recompensada con el engrandecimiento y el bienestar de la humanidad (por José Montero, responsable por Tricotaje) (Producción, 20/8/1937).

Ahora, la ética protestante tenía otra versión: "el trabajo es un esfuerzo que ennoblece el hombre", pero su recompensa no sería en el reino de los cielos, sino para que la humanidad - y no el hombre individual - la disfrutara en la sociedad de los hombres. El trabajo era 
concebido como sacrificio, pareciendo no haber la posibilidad de placer en su contenido; la posibilidad del placer no estaba en la posibilidad del trabajo-creación, sino en la posibilidad lejana de un futuro de bienestar para la humanidad. El stajanovismo estaba restricto a preocupaciones en el ámbito de la organización y de la división racional del trabajo: a la aplicación eficiente de la ciencia, a la invención de nuevas técnicas. Sí de un lado el modelo stajanovista de producción no hizo transformaciones profundas en la división técnica del trabajo, disminuyendo muy poco la distancia entre planeamiento y ejecución, de otro, las propias dinámicas de la colectividad y de la guerra civil invitaban a cada trabajador a constituirse como un hombre nuevo - aquel que es capaz de repensar y rehacer a sí mismo y a su entorno. Al menos, el proceso educativo intentaba esta dirección: la formación del obrero integral y, sin embargo, la reconstitución de la multidimensionalidad humana sería el resultado de un largo proceso.

En el contexto de la guerra civil, la socialización de los medios de producción estaba lejos de representar la conquista del reino de la libertad, más bien se constituiría como uno de los requisitos básicos para intentar garantizar las condiciones mínimas para sobrevivir y resistir al fascismo. En este contexto, el trabajo no podría significar otra cosa, sino esfuerzo y sacrificio - herramienta de construcción de mejores días para la población española. Aun siendo una propiedad colectiva del conjunto de los obreros, los frutos del trabajo y las riquezas producidas no les pertenecían, más bien pertenecían a la causa revolucionaria. De acuerdo con Marx, al trabajar el hombre transforma la naturaleza y a sí mismo, así al trabajar, los hombres y mujeres de Quirós hacían de la naturaleza una de sus fuerzas, contribuyendo para tornar real la posibilidad de creación del nuevo hombre. Mientras el reino de la necesidad y el de la libertad no se tornaban reales, los obreros continuaban produciendo incesantemente - quizás produciendo a un ritmo mayor que en el pasado próximo, pero con Un objetivo distinto del que tenían en la época de los patrones. Ahora, la máxima productividad estaba a servicio de una causa distinta de la anterior: 
(...) Nuestros ex-patronos, esos señores que con sus frases atemorizaban al obrero para que produjera mucho para él, y el obrero, con el temor a que los despidieran, se sacrificaba, se mataba a trabajar, ¿para qué? Para que se quedara el patrono con el producto y el obrero se muriera de asco; eso no debe volver a existir, y eso lo que debemos de evitar nosotros. ¿Cómo? Produciendo (...) debemos poner todos nuestros esfuerzos para aniquilar de una vez el fascismo. Compañeros y compañeras: "Producir" (Producción, 20/2/1937).

Satisfacer las necesidades mínimas era condición sine qua non y, al mismo tiempo, parte integrante del reino de la libertad - y esto no se hacía sin disciplina. El reglamento de la colectividad no dejaba dudas sobre la necesidad de la disciplina:

\begin{abstract}
Art.27 - Será considerado como indeseable dentro de la Colectividad y sancionado incluso con la expulsión todo asociado, cualquiera que sea su responsabilidad, que no observe en su trabajo o en su conducta la mayor disciplina: los saboteadores, los que no observen principios de honradez fundamentales en las masas trabajadoras y los que manifiesten ideales políticos contrarios a los que legítimamente siempre defendieron los trabajadores y por los que lucharon y murieron muchos de ellos.
\end{abstract}

Art.28 - Cuando algún miembro de la Colectividad incurra en falta, que ajuicio del Consejo obrero merecería la expulsión, éste convocará Asamblea de sección, para que ésta, después de oír el informe que presente el Consejo y la justificación que pudiera dar el interesado, determine sobre el particular (Producción, 5/3/1937).

Era una cuestión de vida o de muerte. El objetivo inmediato del trabajo era intentar librar el país de la amenaza del fascismo, así el ideal del buen trabajador era aquel que garantizaba la máxima producción para suplir las necesidades de la guerra. Si en tiempos anteriores la disciplina se imponía por el temor de las represalias, el espíritu de la revolución popular inspiraba otro referencial de disciplina de trabajo: una disciplina espontanea, no forzada por nadie, sino impuesta por el propio trabajador. Al contrario de la época en que la familia Quirós imperaba, el aumento de la productividad no sería un beneficio del capital, sino en beneficio de la propia sociedad, lo que significaba que la disciplina sería no sólo un interés colectivo, sino también de cada un de los trabajadores que serían recompensados en la distribución 
gualitaria de las riquezas producidas. Serían considerados "indeseables" $\mathrm{n}$ la Colectividad todos aquellos $\mathrm{qu}^{\wedge}$ explícitamente se pusieran en ontra de las fuerzas republicanas - fuerzas estas que, tácticamente, epresentaban la posibilidad de instauración del socialismo. Pero, sin mbargo, algunos se pusieron - implícitamente - en contra de la evolución popular, al contribuir excasamente en el éxito de la roducción.

Es preciso no olvidar el corto período que tuvieron los obreros spañoles para intentar la constitución de una nueva cultura del trabajo , creyendo que el futuro se construye como resultado de todo un pasado, $\mathrm{s}$ importante que no dejemos de considerar la historia en su totalidad. esde esta perspectiva merece la pena destacar la encuesta promovida or el Consejo Obrero, cuyo tema era "El trabajo en la Colectividad".

a referida encuesta - respondida por los responsables y encargados e las distintas secciones con el objetivo de evaluar el trabajo del primer ño de socialización de la producción - no escondía la dura realidad olítica de la fábrica. Las propias voces de los trabajadores ilustran las scenas que de alguna manera contrariaban la existencia del espíritu generalizado de un trabajo-sacrificio o de un trabajo abnegado en favor de la revolución popular. Además de la encuesta, otros artículos no esconden la dificultad que tenía el consejo obrero para movilizar a los demás trabajadores para el proyecto político de una nueva sociedad:

Escena 1 (asamblea/intereses individuales)

En la última asamblea que celebramos, ¿cuántos asistieron? Creo que la cuarta parte del personal; con esto está dicho todo. Se siegue trabajando a la fuerza, como en otros tiempos (y creo que menos), para que no le falte a uno el sueldo, debiendo ser todo lo contrario: con cariño, con alegría, como cosa propia. Hay quién tiene el valor de decir que estamos aumentando el capital para cuando vuelvan los jefes; que no se reparten los beneficios entre el personal..., por donde se mire, no se ve más que el egoísmo e interés personal. Pensando así no se va a ninguna parte (por G.Peña, Producción, 20/8/1937). 


\section{Escena 2 (productividad)}

El rendimiento actual del trabajo por el sistema Colectividad tiene, hasta el momento, bastante falta de comprensión por parte de algunos compañeros y compañeras que debido a las anteriores circunstancias, al encontrarse ahora con más libertad de trabajo, se creen con más derechos que antes, llegando incluso a dar menos rendimiento, perjudicando con ello los interés de nuestra colectividad (por Carlos Martins, ibidem).

\section{Escena 3 (clases y biblioteca)}

Todo fue gran animación y entusiasmo durante los primeros días, después... unos faltando a las clases, otros perdiendo el interés que demostraron por la biblioteca; hemos llegado hasta hoy, en que el número de los que verdaderamente se preocupan con la cultura no puede ser más insignificante.(...) De seguir así, no está lejano el día en que nadie se acuerde que tuvimos unas clases, ni que hoy existe una buena biblioteca en nuestra Colectividad (ibidem).

\section{Escena 4 (Socorro Rojo Internacional y otros)}

(...) el S.R.I., otro medio de educación, sigue el mismo camino que clases y biblioteca, si pronto no cambian de derrotero. (...) Siguiendo así nunca pondrá llevarnos este camino a desempeñar cargos de alguna responsabilidad y no sólo eso, sino que es posible que llegue el día en que ni siquiera el trabajo cotidiano podamos sacar adelante (por Mariano Sandonis, ibidem).

\section{Escena 5 (biblioteca 2)}

(...) hay compañeros en nuestra colectividad, que todavía no ha solicitado un sólo libro; más aún: que no conocen la biblioteca (...) La biblioteca lleva abierta 151 días; en estos días sólo se han despachado 568 libros, que hecha la división, nos da 4 libros despachados por día. ¡Atención! De 300 compañeros que somos actualmente, sólo cuatro diarios han solicitado libros; con la particularidad de que estos cuatro, son casi siempre los mismos (Producción, 15/9/1937).

\section{Escena 6 (periódico Producción)}

Vemos con pesar que nuestros compañeros de Asociación están cada día más reacios a enviar algún artículo para nuestro periódico (...) Y esta pequeña redacción se pregunta: ¿Es que una Colectividad como la nuestra, compuesta de más de cuatrocientos trabajadores de ambos sexos, no surgen a cada momento temas interesantísimos y tan varios para poder desarrollarlos en una publicación quincenal? (Producción, 20/5/1937). 
¿PORQUE...

...hay quien cree que nuestro Ferrobellum es un sanatorio?

...hay, en la industria de guerra, compañeras que, estando enfermas para

acudir al trabajo, no lo están para salir de paseo con el novio?

...no recuerdan esas compañeras que serán más gratos los paliques con

el novio después de haber cumplido ellas sus deberes de trabajadores antifascistas?

...una vez leído lo que antecede, consulten el caso con el camarada que

las acompaña, y que seguramente les dirá lo mismo que nosotros?

iFerrobellum, 18/7/1938),

¿Cómo explicar el bajo grado de participación obrera? ¿Cuál era la relación del nivel de movilización con el desarrollo de la guerra? ¿En que medida la vida en las colectividades ya anunciaban/denunciaban una correlación de fuerzas favorable a los nacionalistas? Para los obrerosi hasta donde era posible mantener un trabajo-sacrificio? No pretendemos entrar en los meandros del largo río que produce la subjetividad obrera, pero el hecho es que, a pesar del discurso, no eran muchos aquellos que, de hecho, se proponían tornarse sujetos de su trabajo y de la historia de la colectividad - o como decía Gramsci, tornarse "intelectuales de nuevo tipo", sujetos creadores de sí y del mundo. La realidad de Almacenes Quirós, además de los indicios de Ferrobellum, nos hace inferir que la revolución popular - aunque popular

- no fue, exclusivamente, una revolución del pueblo que luchaba en contra el fascismo y/o en contra del capitalismo. La revolución popular, amen de una lucha para garantizar el derecho democrático de gobernabilidad de las fuerzas republicanas, fue una revolución del pueblo trabajador en búsqueda de días mejores: garantizar las condiciones mínimas de sobrevivencia para sí y su familia. De ahí se explique que encontremos distintos niveles de participación y de compromiso político. Además, nos preguntamos: ¿En que medida el modelo stajanovista de producción - que de alguna manera reproducía la alienación del trabajo - era uno de los elementos que favorecían la fragilidad del compromiso técnico-político de los trabajadores colectivos? 


\section{Por una historia de los diferentes actores de la socialización de la producción}

¿Cuál es el significado del corto período de tiempo en que a los trabajadores de las colectividades les fue posible intentar la creación de una nueva lógica para la producción? La historia de las colectividades obreras y campesinas en la guerra civil es parte integrante de la historia de la praxis humana en su permanente proceso de conocer y transformar la realidad. En este proceso, a medida que los obreros se tornaban en los nuevos dirigentes de la fábrica y de la producción de su existencia, la vida cotidiana en la fábrica se tornaba en una escuela para los trabajadores. Gramsci (1977, p.70), refiriéndose a los consejos de fábrica como una instancia fundamental del sistema de democracia obrera, decía que ellos eran el órgano más idóneo para la educación recíproca del proletariado y para el desarrollo de un nuevo espíritu social; "una magnífica escuela de experiencia política y administrativa" donde "se fundiría una consciencia concreta y eficaz porque habría nacido espontáneamente de la experiencia viva e histórica".

La Asociación Colectiva de Trabajo Almacenes Quirós también representó una escuela para sus obreros y obreras; a lo largo de su historia fue posible percibir las concepciones de sociedad, de trabajo y de educación que los trabajadores intentaban imprimir en la fábrica. El proceso educativo era considerado una condición sine qua non del proceso productivo; trabajo y formación técnico-política eran aspectos fundamentales del proyecto mayor de sociedad, aunque no caminasen en el mismo rumbo. Si de un lado la práctica educativa tenía como perspectiva la socialización de la cultura y la formación del hombre integral, de otra, la organización racional del trabajo, inspirada en los principios stajanovistas/tayloristas, reproducía la separación entre cuerpo y alma, entre pensar y hacer el mundo laboral. La educación "al-pie-dela-fábrica" contribuía, de alguna manera, para promover el acceso a los fundamentos científico-tecnológicos $\mathrm{y}, \sin$ embargo,-las practicas laborales parecían mantener un trabajo mecánico y repetitivo. La 
dicotomía proyecto educativo y proyecto laboral era la manifestación de la falsa dicotomía, instituida por el capital, entre el mundo de la cultura y mundo de la producción y, en síntesis, entre trabajo intelectual y trabajo manual. Aunque "científica", la producción de los bienes materiales era en sí des-educadora/de-formadora, contrariando la perspectiva de un trabajo que reconstituyera la omnilateralidad humana.

Pero ¿qué aspectos de la organización del trabajo permitían y favorecían el proceso de formación de un hombre capaz de crear y recrear el mundo en su entorno? Es importante enfatizar que la participación - considerada como capacidad de decisión e interferencia parecía que pasaba por canales ajenos al taller. Es decir, la posibilidad de participar en las cuestiones relativas al planeamiento general de la fábrica era concebida como algo más allá del acto de producir. La educación técnica, por lo tanto, no era comprendida como la permanente articulación entre teoría y práctica, tanto en lo cotidiano de la producción como en lo cotidiano de la escuela improvisada. En última instancia, la educación era concebida como un momento del trabajo intelectual, y por ende como algo exterior al taller. Sin embargo, la posibilidad de interferencia técnico-política parecía estar garantizada en otros espacios de la fábrica: en las asambleas generales, asambleas y reuniones de sección, en la publicación de artículos en el periódico, en las clases y actividades culturales... en el poder de destituir el consejo obrero, de elegir y elegirse representante de sus compañeros de sección y de fábrica. Pero, como hemos visto, ni todos participaban, ni todos tenían el mismo nivel de compromiso con la fábrica y con la revolución popular. Podemos inferir que la vida cotidiana en las diferentes instancias de las relaciones sociales, al mismo tiempo que reproducía, también contrariaba la organización capitalista del trabajo. La posibilidad de lo "nuevo" era producido a partir de lo "viejo". El stajonovismo - aunque no rompiera con la vieja marca del capital - representaba y anunciaba lo nuevo que era posible en aquel momento histórico.

Sabemos que en las muchas "fábricas-escuelas" que existieron en la guerra civil, fueron distintos sus actores protagonistas y fueron 
muchos sus actores coadyuvantes. Y, de cada actor sería posible oír una versión diferente de una misma Historia. En la conclusión de nuestra investigación no podemos olvidar las diferentes concepciones de sociedad y de trabajo, y tampoco los enfrentamientos entre las fuerzas republicanas. Ahora bien, desde 1868, los anarcosindicalistas españoles ya defendían la revolución integral de los trabajadores para la construcción de una sociedad libre y comunitaria; la revolución no sólo seria económica, sino fundamentalmente cultural y moral, por lo tanto las colectivizaciones no sólo serían una nueva manera de administrar la economía sino las bases de un nuevo modo de vida, basada en la igualdad y solidaridad entre los individuos. Las historias de las colectivizaciones en el período de la guerra civil suelen ser, en general, la historia de la socialización de la producción en el campo, "donde se realizó la experiencia más profunda del comunismo libertario, donde las nuevas prácticas sociales desarrolladas por los campesinos fue algo sorprendente, demonstrando en su trabajo de creación, transformación y socialización una consciencia social muy superior a los obreros industriales de las ciudades" (García, 1977, p.80). Partiéndose del supuesto de que en Madrid las colectividades industriales existieron en número reducido, unos analizan que

(...) la casi inexistencia de colectividades industriales se explica por la autoridad que el Gobierno conservó en Madrid, y por falta de alicientes sindicales - CNT en minoría, UGT sin iniciativas - Eso demuestra que los obreros no querían o no tenían bastante formación para tomar en manos ellos mismos los medios de producción, y que, en línea general, seguían las directivas de sus organizaciones, estuvieran o no en contra de la colectivización, así en Barcelona colectivizaban y en Madrid no (Mintz, 1977, p.115).

Aunque en el movimiento revolucionario el enemigo común fuera el fascismo, no es posible olvidar las profundas divergencias políticas e ideológicas entre las fuerzas de izquierda. Cualquier intento organizado contra el fascismo sólo seria posible con una alianza entre Unión General de Trabajadores (UGT) y Confederación Nacional del Trabajo (CNT), las dos centrales sindicales en las cuales la clase obrera estaba 
organizada y polarizada desde el inicio del siglo. La polarización entre las fuerzas indicaba la necesidad de un pacto estable para llevar adelante las tareas de la revolución, evitando que la lucha interna entre comunistas, anarquistas, socialistas y republicanos dividiera y enflaqueciera el movimiento. Según Garcia (1977, p.86), "la política seguida por los partidos republicanos, por PSOE y de una forma especial por PCE, era contrarevolucionaria: no por ir contra los anarquistas, sino por ir contra la clase obrera y contra la expresión de su práctica revolucionaria, las colectividades obreras y campesinas". De otro lado, no faltaron críticas a los anarquistas, como "aquellos que despreciaban las necesidades prioritarias de los frentes, cuando el problema de guerra contra el fascismo era cuestión de vida o de muerte(...) despreciaban la producción y concentraban todos afanes 'renovadores', toda su demagogia 'ultrarrevolucionaria' en la 'distribución igualitaria'" (Ibarruri, 1966, p.32).

Es posible observar en el periódico Producción, las polémicas acerca de la disciplina y de la organización del trabajo, pero, aunque la problemática de las colectivizaciones obreras lo merezca, el objeto de la presente investigación no fue averiguar en que medida y hasta que momento de la guerra civil fue posible mantener - bajo la hegemonía de los comunistas - la unidad de las fuerzas políticas en el interior de Almacenes Quirós. Lo que ahora consideramos relevante e importante registrar es que, quizás, esta unidad, aunque aparente, haya sido el elemento que nos permitió percibir mejor el contenido del proceso de producción - y con ello las concepciones de trabajo y de educación que fundamentaban las prácticas colectivistas.

De esta corta historia, fue posible extraer algunas pistas que nos invitan a empezar otros estudios sobre la socialización de la producción y la relación trabajo-educación bajo la perspectiva de los propios trabajadores; de ella, también es posible concluir sobre la necesidad de otras investigaciones que privilegien el análisis del significado del trabajo en las colectivizaciones obreras y campesinas desde la perspectiva y la cotidianidad de sus diferentes actores sociales - anarquistas, comunistas, 
trotskista, además de tantos otros obreros que soñaran construir una nueva sociedad tras la victoria de las fuerzas republicanas. La conclusión de una investigación tiene como horizonte la posibilidad de "recomenzar", o incluso de inaugurar una nueva investigación. Para esto creemos que sería necesario plantear nuevas/viejas preguntas: ¿Cómo convivían en una misma colectividad los diferentes actores de la revolución popular? ¿Qué perspectivas de vida, de trabajo, de educación $\mathrm{y}$ de sociedad se manifestaban en los diferentes centros productivos de Madrid ¿En qué talleres y fábricas los obreros intentaron superar el stajanovismo? ¿En que medida el discurso de los consejos obreros era representativo de los deseos y de las prácticas de los demás trabajadores? ¿Cómo convivían sus intereses individuales y sus intereses colectivos? En otras palabras, es necesario ir más allá en el análisis de las colectividades obreras, buscando en sus actividades cotidianas los elementos materiales e inmateriales que nos permitan comprender sus perspectivas de trabajo y de educación - sus límites y sus desafíos.

\section{Referencias bibliográficas}

CABEZA, Manuel Rubio. Diccionario de la guerra civil española. Barcelona: Planeta, 1978.1.1-2.

CAPELLA MARTÍNEZ, Miguel. La industria en Madrid: ensayo histórico crítico de la fabricación y la artesanía madrileñas. Madrid: Artes Gráficas y Ediciones, 1963.t.2.

CARRASQUER, Féüx. Las colectivizaciones en Aragón: vivir autogestionario promesa del futuro, 1986.

COMITÉ DEL CONTROL OBRERO DE UNIÓN RADIO. Boletín decena. Madrid: Unión Radio, mar./abr. 1937.

ESPANHA. Ministerio del Trabajo, Comercio y Industria. [Censo de la población de España]. Madrid, 1920. t.2. 
LA ESPOLETA DE LA VICTORIA. Madrid: [s.n.], ago. 1937; set. 1937. (Portavoz de los trabajadores de Experiencias Comerciales).

FERROBELLUM. Madrid: [s.n.],n.9,14jul. 1937;n.11,29jul. 1937;n.25, 18 jul. 1938. (Órgano de la Central Metalúrgica.).

GARCÍA, Félix. Colectivizaciones campesinas y obreras en la Revolución Española. Bilbao: Zero, 1977.

GRAMSCI, Antonio. Os intelectuais e a organizagao da cultura. Rio de Janeiro: Civilizacáo Brasileira, 1982.

GRAMSCI, Antonio, BORDIGA, Amadeo. Debate sobre los consejos de fábrica. Barcelona: Anagrama, 1977.

HOY. Madrid: Comercial de Hierros, n.5, ago. 1937; n.6, set. 1937. (Portavoz de Comercial de Hierros).

IB ARRURI, Dolores et al. Guerra y revolución en España, 1936-1939. Moscú: Progreso, 1966. t.2.

JACKSON, Gabriel. La república española y la guerra civil. Barcelona: Critica, 1990.

KOSIK, Karel. Dialetica do concreto. Rio de Janeiro: Paz e Terra, 1976.

MACHADO, Antonio. Antología poética. Madrid: Alianza, 1995.

MINTZ, Frank. La autogestión en la España revolucionaria. Madrid: La Piqueta, 1977.

PRODUCCIÓN. Madrid: [s.n.], n.1, 20 jan. 1937; n.2, 5 feb. 1937; n.3,20 feb. 1937; n.4, 5 mar. 1937; n.5, 20 mar. 1937; n.6, 5 abr. 1937; n.8, 5 mayo 1937, n.9, 20 mayo 1937, n.1 1, 20 jul. 1937; n.12, 20 ago. 1937; n.13,15set. 1937;n.14;5out. 1937;5nov. 1937. (Órgano de Asociación Colectiva de Trabajo Almacenes Quirós). 
VESTIDO. Madrid: Union General de los Trabajadores. Madrid, n. 1,15 mar. 1937; n.11, 15 set. 1937. (Portavoz del Sindicato de Trabajadores de la Industria del Vestido).

Recebido em 9 de setembro de 1995.

Lia Vargas Tiriba, doutora em Sociologia Economica e do Trabalho pela Universidad Complutense de Madrid-Espanha, e professora assistente na Faculdade de Educacao da Universidade Federal Fluminense (UFF).

Constituting itself as a popular struggle front against the fascism, the Spanish civil war (1936-1939) promoted meaningful changes in the structure of the State and in the different instances of the society. Socialized the means of production, the worker collectivities and peasants tested the first steps in search of an other logic for the articulation between world of the culture and world of production, toward the construction of a new inspirational social order according to the principles of the socialism. In this article we reconstitute the history of the Asociacion Colectiva de Trabajo Almacenes Quiros (ACTAQ) and in order that to understand the dimensions of the relationship work-education in the interior of the factory, we ask ourselves: In the political, economic and social context of the popular revolution, which were the challenges of the production? Which the objectives of the Worker Council in the education process of the other collective workers? What work and world conceptions were underlying in the educational project? In what extent occupational practices, inspired in the stajanovist principles, went in opposite sense to the ideal of man and of society? In what measure the daily life in the "factory-floor" was contradicting/was reproducing the logic of capitalistic organization of the work?

En se constituant comme un front populaire contre lefascisme, la guerre civile espagnole (1936-1939) a promu des changements pleins de sens dans la structure de I 'Etat et dans les instances differentes de la societe. Socialises les moyens de production, les collectivities des ouvriers et pay sans 
ont testé les premiers pas dans la recherche d'une autre logique pour l'articulation entre monde de la culture et monde de la production, vers la construction d'un nouveau ordre social inspiré dans les principes du socialisme. Dans cet article, nous reconstituons l'histoire de l 'Asociación Colectiva de Trabajo Almacenes Quirós (ACTAQ) et, pour comprendre les dimensions du rapport travail-éducation dans l'intérieur de l'usine, nous demandons: Dans les contextes politique, économique et social de la révolution populaire, quels étaient les défis de la production? Quels étaient les objectifs du Conseil de l'Ouvrier dans l'éducation des autres ouvriers colectifs? Quelles conceptions du travail et du monde étaient sousjacentes au projet éducatif? Dans quelles mesures les practiques labourales, inspirées dans les principes stajanovistes ont résisté I 'ideal de l'homme et de société? Dans quelle mesure la vie quotidienne dans l'usine contredisait/ reproduisait la logique de l'organisation capitaliste du travail?

Al constituirse como un frente popular de lucha contra el fascismo, la guerra civil española (1936-1939) promovió cambios significativos en la estructura del Estado y en las diferentes instancias de la sociedad. Socializados los medios de producción, las colectividades obreras y campesinas ensayaron los primeros pasos en búsqueda de otra lógica para la articulación entre mundo de la cultura y mundo de la producción, hacia la construcción de un nuevo orden social inspirado en los principios del socialismo. En este articulo reconstituimos la historia de la Asociación Colectiva de Trabajo Almacenes Quirós (ACTAQ) y, para comprender las dimensiones de la relación trabajo-educación en el interior de la fábrica, nos preguntamos: En el escenario político, económico y social de la revolución popular ¿cuáles eran los desafíos de la producción? ¿Cuáles los objetivos del Consejo Obrero en el proceso de educación de los demás trabajadores colectivos? ¿Qué concepciones de trabajo y de mundo estaban subyacentes en el proyecto educativo? En qué medida las prácticas laborales, inspiradas en los principios stajanovistas, iban en sentido contrario al ideario de hombre y de sociedad? ¿En qué medida la vida cotidiana "al pie-de-la-máquina" contrariaba/reproducía la lógica de la organización capitalista del trabajo? 